\title{
Using Geographically Weighted Regression to Assess the Relationship Between Weather and Sociodemographic Indicators and COVID-19 Infection in Iraq
}

Azad Rasul ( $\sim$ azad.rasul@soran.edu.iq )

Soran University https://orcid.org/0000-0001-5141-0577

Saad Ibrahim

Adamu Augie College of Education

\section{Research Article}

Keywords: GWR, COVID-19 pandemic, coronavirus environmental factors, infection, SARS-CoV2, novel coronavirus in Iraq, sociodemographic factors, disease, temperature

Posted Date: November 16th, 2021

DOl: https://doi.org/10.21203/rs.3.rs-985293/v1

License: (1) This work is licensed under a Creative Commons Attribution 4.0 International License. Read Full License 


\section{Abstract}

The impact of COVID-19 is still being recognised due to increased research, demand for the communication of uncertainties and evidence based information to help decision makers to design appropriate mitigation policies overtime. Weather and sociodemographic indicators are important to comprehensively understand rapid spread of the disease at a given spatial scale. The spatial pattern in the occurrence of disease may hint at the mechanisms that produce the disease, hence spatial analysis is very useful in studying the causes of a disease. This study evaluates the influence of weather variables, sociodemographic characteristics and their corresponding records of COVID-19 in Iraq cities. The assessments of these relationships were based on $R_{0}$ estimated from the time series data of COVID-19 infections, and by using geographically weighted regression (GWR) and linear regression modelling. Global estimates of these relationships from the linear regressions are generally poor. On the contrary, the results derived from the GWR show spatially varying patterns. The lag7 of weather variables performed better compared to other lags. Among weather variables, increasing wind speed leads to risen COVID-19 infection. Population density is one of the sociodemographic characteristics that contributes to higher COVID-19 infection. COVID-19 infections, on the other hand, decreased in cities with a good health index and access to piped water. The findings of this study are therefore of great value to policy makers to design appropriate measures to reduce COVID-19 infection in Iraq and elsewhere.

\section{Introduction}

SARS-CoV2 is increasingly recognised as an important, worldwide public health concern. The number of confirmed cases and casualties of SARS-CoV2, at a global scale, has significantly increased. These have drawn the attention of researchers and policy-makers to devise measures against the rapid development of the diseases by providing guidance and options for a better healthcare delivery needed to address the prevailing and future challenges (Eker 2020). It has been postulated that the peak time of the transmission of these diseases is most peculiar to a specific season and weather conditions, for instance, the peak of SARS-CoV1 occurred during the spring while MERSCoV was transmitted in the warm climate during spring and summer seasons (Caspi et al. 2020). In contrast, the transmission of influenza shows seasonality in the regions with a temperate climate where the peak of infections happens during winter (Bukhari and Jameel 2020; Sajadi et al. 2020; Rasul 2021).

The spread of COVID-19 could be influenced by weather and climatic variables and human demographic variables such as population density, culture, and country measures against the disease (Caspi et al. 2020). At the global scale, association between per country COVID-19 cases and principal climatic variables were examined by previous studies (Rasul 2021). The research reported a significant weak inverse relationship between $R_{0}$ of COVID-19 cases and wind speed. At the local scale, some research were carried out to evaluate the association between COVID-19 disease and climatic variables. For instance, in Iran, a study reported that COVID-19 infection is high in cities with low degrees of wind speed, humidity, and solar radiation (Ahmadi et al. 2020). In China, linear regression was used to assess the impact of temperature in the cities. Results indicated that high temperatures and high humidity significantly reduced the spread of COVID-19 in 100 cities (Wang et al. 2020). A tropical case study, in Rio de Janeiro, Brazil, concludes that the spread of COVID-19 could be suppressed by a high solar radiation (Rosario et al. 2020). In Jakarta, Indonesia, results display COVID-19 pandemic is weakly positively correlated with average temperature (Tosepu et al. 2020).

To date, only weak evidence is provided by peer reviewed published papers confirming that SARS-CoV- 2 is more transferrable under lower air temperatures and low absolute humidity. In addition, the reported relationships between SARS-CoV-2 and air pollution, UV, and wind speed are ambiguous. There is, therefore, the need for the researchers to critically investigate the influence of environmental and weather on the virus and the disease. This means that the impact of weather and climate variables on COVID-19 infection is not only localized but also at experimental stages.

One another question is whether socio-economic and socio-demographic variables of the people may affect the transmission of COVID19 infection. The influence of these variables on the spread of COVID-19 infection is still not well understood. The example of these variables are population size, population density, the degree of urbanization and poverty (Smit et al. 2020). Despite the fact that different results were reported in the literature about the influence of the environmental conditions on the COVID-19, it is still quite imperative to study the influence of the daily weather and sociodemographic elements on the virus in Iraq (at the local scale). In addition, having more observations and dense time series data regarding the new Coronavirus can reveal pattern that may not have been explored in the past, perhaps by using strict hypotheses and the development of analytical methods and statistical models(Smit et al. 2020). The use of GWR for evaluating the relationships between environmental and human factors and COVID-19 has been not been adequately researched.

In this study, we aimed to investigate whether COVID-19 detection is related to weather elements and sociodemographic indicators in Iraqi cities, which is important to comprehensively understand the factors that contribute to rapid spread of the disease at a given spatial

Page 2/11 
scale. Specifically, we evaluated the relationship between weather and climate elements and sociodemographic variables and COVID-19 using GWR and Multiple Linear Regression (MLR). A recent study by Wu and Zhang (Wu and Zhang 2021), who explore the spatialtemporal varying impacts on cummulative case in Texas using GWR, emphasized that there is a lack of country level research on COVID19 GWR modeling. The findings should make an important contribution to policy makers to enable them to prepare measures and strategize against this disease.

\section{Materials And Methods}

\subsection{Data}

Data of daily the affected people with COVID-19 in each Iraqi governorates were collected from daily announcements of Iraqi Ministry of Health (moh.gov.iq 2020). The data collected started from 24th of February, which is the first day of COVID-19 detection in Iraq to 31 st of December 2020. Daily data of weather elements (air temperature, relative humidity, dewpoint, atmospheric pressure, visibility and wind sped) across weather stations in the country were obtained using "worldmet" package of R programming (Carslaw 2020). Surface meteorological data of Iraqi weather stations were downloaded by the package from NOAA Integrated Surface Database (ISD). The sociodemographic data such as health index, density, urbanization and mean years schooling were downloaded from Global Data Lab, Institute for Management Research, Radboud University (GDL 2020).

\subsection{Statistical analysis}

In the $R_{0}$ estimations, to make an accurate rate of transmission, only those data after 30 cases of COVID-19 were reported in each governorate was used (Smit et al. 2020). The basic $R_{0}$ transmissibility projection based on Cori's et al. (2013) framework was adopted in this study. This method generates robust analytical speculates of $R$. if the result of $R_{0}$ is higher than 1 , it means the virus is spreading rapidly(Team 2014). This estimates of $R_{\mathrm{t}}$ from time series of cases provides the $R_{0}$ of the endemic(Cori et al. 2013).

Association between $R_{0}$ of the daily confirmed cases of COVID-19 of Iraqi governorates and daily weather variables were assessed. We converted the hourly data of downloaded weather stations to daily data before data analyses. Geographically weighted regression (GWR) and Multiple Linear Regression (MLR) methods were applied to quantify the linear and spatial relationships.

Statistical analyses were executed in R programming (e.i. spgwr (2020) and sp (2021) packages). In this study GWR, multivariate regression was performed and preferred over univariate regression. GWR is localized regression that suggested by Brunsdon et al. (1996) which assess non-stationary variables (Zhou and WANG 2011). The model is stated as (Equation 1) and MLR expressed as (Equation 2).

$$
y_{i}=\beta_{0}\left(u_{i}, v_{i}\right)+\sum_{k} \beta_{k}\left(u_{i}, v_{i}\right) x_{i k}+\epsilon_{i}
$$

1

where $\left(u_{i}, v_{i}\right)$ implies the coordinates of the $i$ th point in space, $\beta_{0}$ and $\beta_{k}$ are parameters to be estimated, and $\epsilon_{i}$ is the random error term at point $i$.

$$
y=b_{0}+b_{1} x_{1}+b_{2} x_{2}+\cdots+b_{n} x_{n}
$$

2

where $y$ dependent variable, $b_{0}$ y-intercept, $x$ explanatory variables, $b_{n}$ slop for $x_{n}$.

\section{Results}

\subsection{Relationship between daily climatic variables and $R_{0}$ of COVID-19 in Iraq}

Table 1 indicated that at the global scale, the highest positive regression coefficients with wind speed was on the same day (0.04) while the highest relationship with air temperature was found in the lag7 (0.03). with regards to visibility, the highest coefficient was during lag3 and lag7. Based on GWR at local coefficients, the strongest relationship of wind speed was during the same day while regarding temperature and visibility, the highest relationship was during lag7. In general, lag7 performed better than the sameday, lag3 and lag14; therefore, we choose lag7 in this research for further analysis. 
The relationship between daily data of climatic factors and lag7 of the $R_{0}$ index of COVID-19 cases in Iraq is depicted in Table 1 and Figure 1. Based on MLR method and global regression, only temperature and dew point have significantly relationship with lag7 of $R_{0}$ COVID-19 infection. In particular, air temperature and wind speed had positively relationship with COVID-19 infection and increasing temperature and wind speed could potentially increase COVID-19 infection by 0.027 and 0.022 , respectively, per unit. In contrast, dewpoint, visibility, and air pressure were found to have negative relationship with COVID-19 infection (Table 2).

At local coefficients, GWR method showed a positive coefficient COVID-19 infection with wind speed in most parts of Iraq with the exception of two cities in the southern part of the country in which negtive relationship was found (Figure 1). It is also positive with air temperature in most parts of the country. And only negative in some cities in the north of Iraq. Regarding air pressure and relative humidity (rh), the relationship varies, as there are positive as well as negative relationships in different cities.

Table 1

Summary statistics of GWR coefficient parameter estimates between daily climatic variables and $R_{0}$ of COVID-19 in Iraq.

\begin{tabular}{|c|c|c|c|c|c|c|c|c|}
\hline & & Intercept. & Wind speed & $\begin{array}{l}\text { Average } \\
\text { temperature }\end{array}$ & Visibility & Dewpoint & Air pressure & $\begin{array}{l}\text { Relative } \\
\text { humidity }\end{array}$ \\
\hline \multirow[t]{4}{*}{ sameday } & Min. & -106.1619809 & -0.15334338 & -0.24666453 & -0.00013816 & -0.15298225 & -0.03906316 & -0.13344508 \\
\hline & Median & -7.26541098 & 0.06811050 & 0.02756674 & -0.00000874 & -0.04911834 & 0.00656423 & 0.00420095 \\
\hline & Max & 38.73352149 & 0.54194817 & 0.14471235 & 0.00027898 & 0.45461500 & 0.10850927 & 0.04322863 \\
\hline & Global & -2.32 & 0.04 & 0.02 & -0.0000128 & -0.02 & 0.00 & 0.00 \\
\hline \multirow[t]{4}{*}{ lag3 } & Min. & -69.98474562 & -0.04238865 & -0.21381382 & -0.00021990 & -0.14115175 & -0.04667909 & -0.11244928 \\
\hline & Median & -4.19566953 & 0.03413745 & 0.03292642 & -0.00000432 & -0.04436185 & 0.00457447 & 0.00313093 \\
\hline & Max. & 54.35477726 & 0.33552586 & 0.13648146 & 0.00004117 & 0.38756593 & 0.06920664 & 0.03906694 \\
\hline & Global & 4.83 & 0.02 & 0.02 & -0.000013 & -0.03 & 0.00 & 0.00 \\
\hline \multirow[t]{4}{*}{ lag7 } & Min. & -49.47200016 & -0.01520483 & -0.10655229 & -0.00005979 & -0.12415552 & -0.02306602 & -0.04893921 \\
\hline & Median & -1.95682000 & 0.04464416 & 0.05367760 & 0.00000967 & -0.04313849 & 0.00163355 & 0.00651165 \\
\hline & Max. & 25.32121949 & 0.39912796 & 0.10011727 & 0.00005543 & 0.13143141 & 0.04777453 & 0.03111244 \\
\hline & Global & 5.80 & 0.02 & 0.03 & -0.000013 & -0.04 & 0.00 & 0.00 \\
\hline \multirow[t]{4}{*}{$\operatorname{lag} 14$} & Min. & -53.2131888 & -0.1159604 & -0.0656764 & -0.0001745 & -0.1062252 & -0.0696265 & -0.0538905 \\
\hline & Median & 24.9945008 & -0.0091572 & -0.0209680 & 0.0000389 & -0.0272174 & -0.0240789 & -0.0078970 \\
\hline & Max. & 74.3389385 & 0.5676336 & 0.0701429 & 0.0002926 & 0.0704752 & 0.0565672 & 0.0252927 \\
\hline & Global & 29.52 & 0.01 & -0.01 & 0.0000123 & -0.02 & -0.03 & -0.01 \\
\hline
\end{tabular}


Table 2

Statistics of regression between climatic variables and lag7 $R_{0}$ of COVID-19 in Iraq based on the Multiple Linear Regression method.

\begin{tabular}{|c|c|c|c|c|}
\hline & Estimate & Std.Error & tvalue & $\operatorname{Pr}(>|t|)$ \\
\hline Intercept & 5.8001948 & 7.6804758 & 0.76 & 0.4502 \\
\hline ws & 0.0217733 & 0.0172550 & 1.26 & 0.2071 \\
\hline temp & 0.0275270 & 0.0151045 & 1.82 & 0.0685 \\
\hline viss & -0.0000130 & 0.0000316 & -0.41 & 0.6801 \\
\hline dew & -0.0446824 & 0.0148010 & -3.02 & 0.0026 ** \\
\hline pre & -0.0047871 & 0.0073539 & -0.65 & 0.5151 \\
\hline rh & 0.0007408 & 0.0061386 & 0.12 & 0.9040 \\
\hline
\end{tabular}

\subsection{Relationship between the sociodemographic variables and COVID-19 infection of Iraq}

After assessing relationship between weather variables and $R_{0}$ of COVID-19 infection in the last section, we selected a list of sociodemographic variables to analyses how they are associated with cumulative number of COVID-19 infections in Iraqi Governorates. At global scale, as the Table 3 indicated, COVID-19 infection has positive relationship with ten of the variables assessed, such as subnational human development index and the number of population of the governorates. In contrast, negative relationships were observed with five of the sociodemographic variables such as health index, having piped water, and human development index. This means the risk of COVID-19 infection reduces in cities with high health index and availability of piped water, compared to cities with a low health index and less availability of piped water. However, based on LMS method the association between sociodemographic variables and COVID-19 infection was only statistically significant with population density $(p<0.01)$ and the total number of people (population) ( $p$ $<0.05)$.

GWR method shows that the relationship between sociodemographic variables and the number of COVID-19 infections does not strongly vary spatially. Population $65+$ is the only variable that shows striking difference in terms of the relationship with COVID-19 infection. Negative relationship was found in most parts of the country. However, apositive GWR coefficient was found in northern Iraq (Table 4 and Figure 2). Regression coefficients of the number of population and population density are positive and do not vary significantly around the cities for the entire country. 
Table 3

Statistics of regression between sociodemographic variables and COVID-19 infection of Iraq based on the Multiple Linear

Regression method. (A) Subnational Human Development Index, (B) Health Index, (C) Standard of Living Index, (D) Education

Index, (E) Life expectancy, (F) Gross National Income per Capita,

(G) \% Piped water, (H) Dependency ratio, (I) \% Pop 65+, (J) Old depratio, (K) \% Pop <15, (L) Population in millions, (M) Urbanization, (N) Density, (O) Human Development Index.

\begin{tabular}{|c|c|c|c|c|}
\hline & Estimate & Std. Error & t value & $\operatorname{Pr}(>|t|)$ \\
\hline (Intercept) & -287869.54 & 1732008.56 & -0.17 & 0.883 \\
\hline$A$ & 1656324.66 & 1823172.91 & 0.91 & 0.46 \\
\hline$B$ & -320020.4 & 1228188.64 & -0.26 & 0.819 \\
\hline $\mathrm{C}$ & 210799.44 & 1386858.68 & 0.15 & 0.893 \\
\hline $\mathrm{D}$ & 473037.26 & 1729363.14 & 0.27 & 0.81 \\
\hline$E$ & 11690.55 & 32312.89 & 0.36 & 0.752 \\
\hline $\mathrm{F}$ & 5.59 & 12.38 & 0.45 & 0.696 \\
\hline $\mathrm{G}$ & -83.68 & 216.57 & -0.39 & 0.736 \\
\hline $\mathrm{H}$ & -14079.64 & 15989.38 & -0.88 & 0.471 \\
\hline I & -2982.18 & 129882.32 & -0.02 & 0.984 \\
\hline $\mathrm{J}$ & 27005.32 & 59660.81 & 0.45 & 0.695 \\
\hline $\mathrm{K}$ & 37518.96 & 51181.35 & 0.73 & 0.54 \\
\hline $\mathrm{L}$ & 10758.44 & 3603.79 & 2.99 & 0.096 . \\
\hline$M$ & 213.46 & 579.23 & 0.37 & 0.748 \\
\hline $\mathrm{N}$ & 68.14 & 12.55 & 5.43 & $0.032 *$ \\
\hline 0 & -3657496.92 & 5542750.1 & -0.66 & 0.577 \\
\hline \multicolumn{5}{|c|}{ 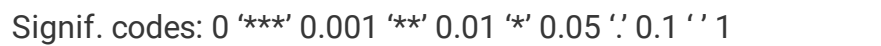 } \\
\hline
\end{tabular}


Table 4

Parameter coefficients of the multivariate regression model between sociodemographic variables and COVID-19 infection of Iraq based on the GWR method.(A) Subnational Human

Development Index, (B) Health Index, (C) Standard of Living Index, (D) Education Index, (E) Life expectancy, (F) Gross

National Income per Capita, (G) \% Piped water, $(H)$ Dependency ratio, (I) \% Pop 65+, (J) Old depratio, (K) \% Pop <15, (L)

Population in millions, (M) Urbanization, (N) Density, (O) Human Development Index.

\begin{tabular}{|lllll|}
\hline & Min. & Median & Max. & Global \\
\hline Intercept & -365772 & -327835 & -238911 & -287870 \\
\hline A & 1607246 & 1666619 & 1704867 & 1656325 \\
\hline B & -356703 & -342369 & -305961 & -320020 \\
\hline C & 158923.4 & 238869.9 & 267836.6 & 210799.4 \\
\hline D & 361430.5 & 438192 & 553979 & 473037.3 \\
\hline E & 10425.84 & 11895.66 & 12945.78 & 11690.55 \\
\hline F & 4.72 & 5.05 & 5.89 & 5.59 \\
\hline G & -99.56 & -92.1 & -70.99 & -83.68 \\
\hline H & -14446.7 & -14242.2 & -13815.1 & -14079.6 \\
\hline I & -12138.3 & -3332.25 & 5370.89 & -2982.18 \\
\hline J & 23320.26 & 27423.55 & 31006.09 & 27005.32 \\
\hline K & 36086.69 & 38119.88 & 38863.33 & 37518.96 \\
\hline L & 10676.89 & 10882.88 & 10956.77 & 10758.44 \\
\hline M & 183 & 227.27 & 255.39 & 213.46 \\
\hline N & 67.18 & 67.51 & 68.72 & 68.14 \\
\hline O & -3868309 & -3604014 & -3344416 & -3657497 \\
\hline
\end{tabular}

\section{Discussion}

In this study, the correlation between weather and climatic variables (e.g. air temperature, relative humidity, dew point, atmospheric pressure, visibility and wind speed), sociodemographic variables (e.g. subnational human development index, health index, standard of living index, population in millions, urbanization, passenger per airport, density etc.) and their corresponding records of the COVID-19 infection were analysed in Iraq. Weather factors and sociodemographic variables can trigger the spread of Coronavirus infection (Ahmadi et al. 2020; Bashir et al. 2020; Tosepu et al. 2020).

In general, this research shows that the lag7 of COVID-19's $R_{0}$ performed better than the same day, lag3 and lag14. Based on global regression, air temperature significantly and positively correlated with lag7 of $R_{0}$ COVID-19 infection, however, covid-19 infection is not sensitive to air temperature in Iraqi cities because the peak of covid-19 infection occurred during the summer and winter. Local coefficients of COVID-19 infection with wind speed and air temperature based on GWR show a positive coefficient in most parts of Iraq.

A study by Tosepu et al. (2020) who studied the correlation between weather and Covid-19 pandemic in Jakarta, Indonesia found that only average temperature significantly correlated with COVID-19 pandemic $(r=0.392, p<.01)$. Another study by Bashir et al. (2020) found that both average temperature, minimum temperature and air quality have a significant correlation with COVID-19 epidemic in New York, United State of America (USA). These findings are supporting the view that presently there is no scientific evidence yet that warm weather would reduce COVID-19 epidemic (Bashir et al. 2020; Engelbrecht and Scholes 2020).

Furthermore, the relationships between the 15 potential sociodemographic characteristics of the referenced population and their corresponding records of COVID-19 infection were investigated. The results indicated that the relationships between sociodemographic 
variables and COVID-19 infection were statistically significant and strongly positive with population density $(p<0.01)$ and the number of population $(p<0.05)$. Based on GWR this positive association, do not vary around the cities in Iraq (Table 3 and Figure 2).

Our result on the relationship between the population density and Coronavirus infection is similar to the findings Rashed et al. (2020) who studied the influence of absolute humidity, temperature and population density on COVID-19 spread and decay durations in Japan, discovered that population density was shown to be a major factor, affecting the spread and decay patterns (Rashed et al. 2020). Similarly, a study on COVID-19 pandemic which calculates the relative risk of the importation and exportation of the COVID-19 virus from every airport in local municipalities around the world, based on global spatial and mapping information demonstrates that a larger reduction in air travel (in high risk areas) through airports would lead to a gradual decrease in the risk flow. They further emphasized that airport management or government with airports in their jurisdiction should employ stringent countermeasures (Nakamura and Managi 2020).

One of the most important contributions of this study is that it offers some important insights into the influence of varied environmental factors, climatic extremity and sociodemographic factors for assessing their influence on COVID-19 infection in Iraq. This is a holistic approach and therefore remarkable at the time policy makers are looking for options to design mitigation policies to contain and prevent this disease. The influence of seasonality on COVID-19 is still uncertain. Some studies have so far postulated that there is a likelihood for a seasonality-sensitive subsequent waves of infections about one year after the initial outbreak (Engelbrecht and Scholes 2020). This means that due attention requests to be on policy design in order to flatten the curve. Specifically, there is a requirement to design policies on the most important sociodemographic factors as revealed by this study, such as those on travel restrictions and social distancing.

\section{Conclusions}

This study was set out to evaluate the influence of weather and climate, and sociodemographic variables on COVID-19 infection in Iraq, using the GWR and MLR method. The main findings were that the lag7 of weather variables performed better compared to other lags. Among weather variables increasing wind speed leads to risen COVID-19 infection however covid-19 infection is not sensitive to air temperature in Iraqi cities because the peak of covid-19 infection occurred during the summer and winter. Among sociodemographic variables, the population density leads to more high COVID-19 infection than others. In contrast, COVID-19 infections declined in cities with high health index and access to piped water.

This study recommends to policy makers the need for due attention, proper control and prevention, specifically, there is need to design or strengthen policies on the most important sociodemographic factors as revealed by this study, such as social distancing. We acknowledged the limitation of our study due to uncertainties arising from the data, for example given the delays in the development of symptoms and testing of the infected persons, which may lead to under-accounting of the confirmed cases.

\section{Declarations}

\section{Funding:}

This research received no external funding.

\section{Conflicts of Interest:}

The authors declare no conflict of interest.

\section{Author Contributions:}

AR, SI: Conceptualization; AR, Sl; Data curation, Formal analysis; Methodology; AR, Sl; Visualization; AR; Writing - original draft, review \& editing SI, AR

\section{Availability of data and material:}

produced and used data available online on GitHub: https://github.com/Azad77/Relationship_Climate_and_R0_Covid19

\section{Code availability:}

All source codes are publicly available on GitHub: https://github.com/Azad77/Relationship_Climate_and_R0_Covid19 


\section{Ethics approval:}

Not applicable, because this article does not contain any studies with human or animal subjects.

\section{Consent to participate:}

Not applicable.

\section{Consent for publication:}

Not applicable.

\section{References}

1. Ahmadi M, Sharifi A, Dorosti S, et al (2020) Investigation of effective climatology parameters on COVID-19 outbreak in Iran. Science of The Total Environment 138705

2. Bashir MF, Ma B, Komal B, et al (2020) Correlation between climate indicators and COVID-19 pandemic in New York, USA. Science of The Total Environment 138835

3. Bivand R, Yu D, Nakaya T, et al (2020) Package 'spgwr.' R software package

4. Brunsdon C, Fotheringham AS, Charlton ME (1996) Geographically weighted regression: a method for exploring spatial nonstationarity. Geographical analysis 28:281-298

5. Bukhari Q, Jameel Y (2020) Will coronavirus pandemic diminish by summer? Available at SSRN 3556998

6. Carslaw D (2020) worldmet: Import Surface Meteorological Data from NOAA Integrated Surface Database (ISD). Version 0.9.0URL https://CRAN.R-project.org/package=worldmet

7. Caspi G, Shalit U, Kristensen SL, et al (2020) Climate effect on COVID-19 spread rate: an online surveillance tool. medRxiv

8. Cori A, Ferguson NM, Fraser C, Cauchemez S (2013) A new framework and software to estimate time-varying reproduction numbers during epidemics. American journal of epidemiology 178:1505-1512

9. Eker S (2020) Validity and usefulness of COVID-19 models. Humanities and Social Sciences Communications 7:1-5

10. Engelbrecht FA, Scholes RJ (2020) Test for Covid-19 seasonality and the risk of second waves

11. GDL (2020) Global Data Lab - Innovative Instruments for Turning Data into Knowledge. In: GDL Area Database (3.7.0). https://globaldatalab.org/. Accessed 6 Sep 2020

12. moh.gov.iq (2020) The daily epidemiological situation of the new Corona pandemic in Iraq. In: moh.gov.iq. https://moh.gov.iq/. Accessed 6 Sep 2020

13. Nakamura H, Managi S (2020) Airport risk of importation and exportation of the COVID-19 pandemic. Transport Policy 96:40-47

14. Pebesma E, Bivand, Rowlingson, Gomez-Rubio (2021) Classes and Methods for Spatial Data [R package sp version 1.4-5]. https://CRAN.R-project.org/package=sp. Accessed 8 Jun 2021

15. Rashed EA, Kodera S, Gomez-Tames J, Hirata A (2020) Influence of absolute humidity, temperature and population density on COVID19 spread and decay durations: Multi-prefecture study in Japan. International Journal of Environmental Research and Public Health 17:5354

16. Rasul A (2021) Relationship between Climatic Variables and Reproduction Number (R0) of Confirmed COVID-19 Cases. In Review

17. Rosario DK, Mutz YS, Bernardes PC, Conte-Junior CA (2020) Relationship between COVID-19 and weather: Case study in a tropical country. International Journal of Hygiene and Environmental Health 229:113587

18. Sajadi MM, Habibzadeh P, Vintzileos A, et al (2020) Temperature and latitude analysis to predict potential spread and seasonality for COVID-19. Available at SSRN 3550308

19. Smit AJ, Fitchett JM, Engelbrecht FA, et al (2020) Winter Is Coming: A Southern Hemisphere Perspective of the Environmental Drivers of SARS-CoV-2 and the Potential Seasonality of COVID-19. International Journal of Environmental Research and Public Health 17:5634

20. Team WER (2014) Ebola virus disease in West Africa-the first 9 months of the epidemic and forward projections. New England Journal of Medicine 371:1481-1495

21. Tosepu R, Gunawan J, Effendy DS, et al (2020) Correlation between weather and Covid-19 pandemic in Jakarta, Indonesia. Science of The Total Environment 138436 
22. Wang J, Tang K, Feng K, Lv W (2020) High temperature and high humidity reduce the transmission of COVID-19. Available at SSRN 3551767

23. Wu X, Zhang J (2021) Exploration of spatial-temporal varying impacts on COVID-19 cumulative case in Texas using geographically weighted regression (GWR). Environmental Science and Pollution Research 1-15

24. Zhou X, WANG Y-C (2011) Dynamics of Land Surface Temperature in Response to Land-Use/Cover Change. Geographical Research 49:23-36

\section{Figures}

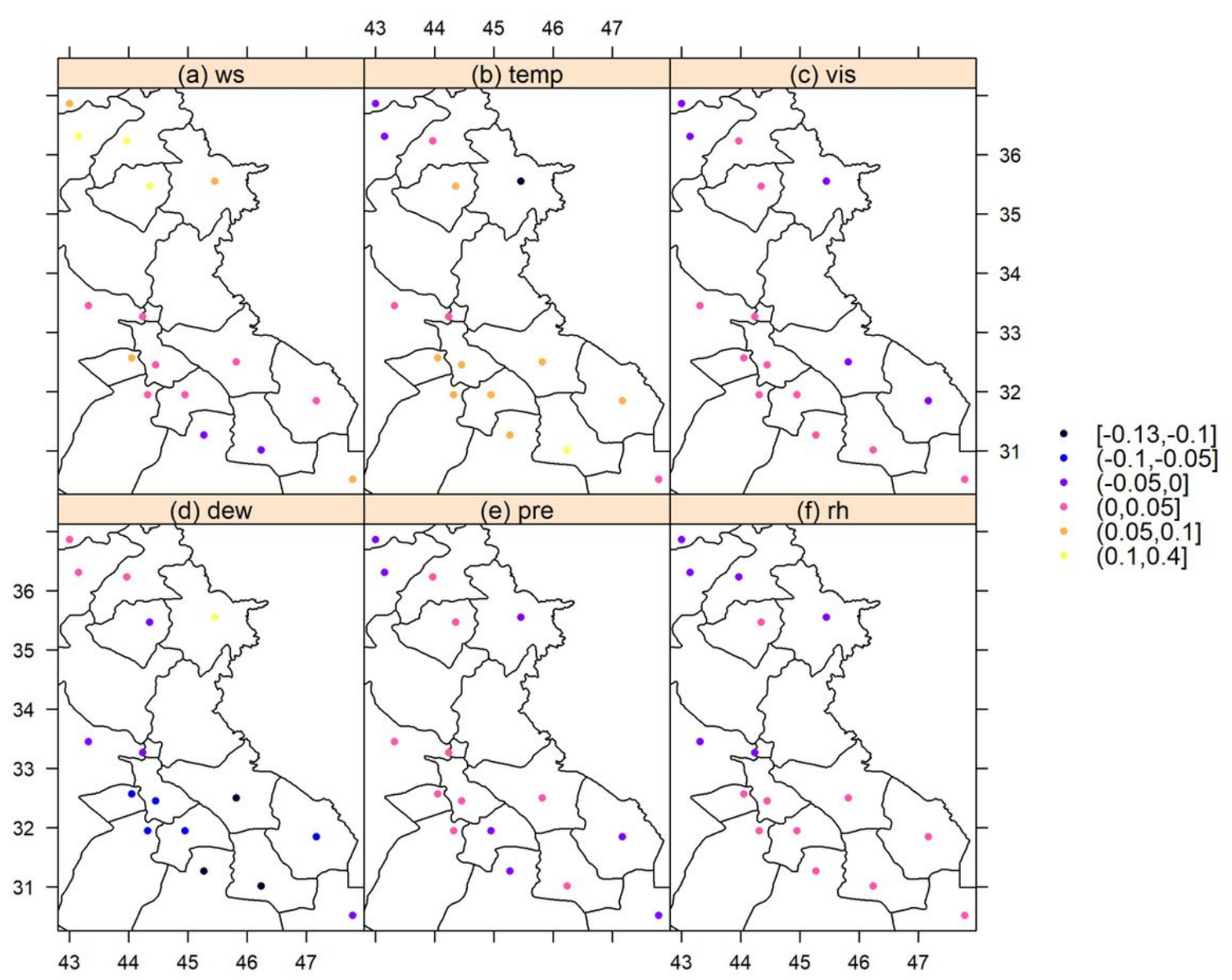

Figure 1

GWR of lag7 R0 of COVID-19 in Iraqi Governorates and daily climatic data. (a) wind speed, (b) average air temperature, (c) visibility, (d) dewpoint, (e) atmospheric pressure and (f) relative humidity. 


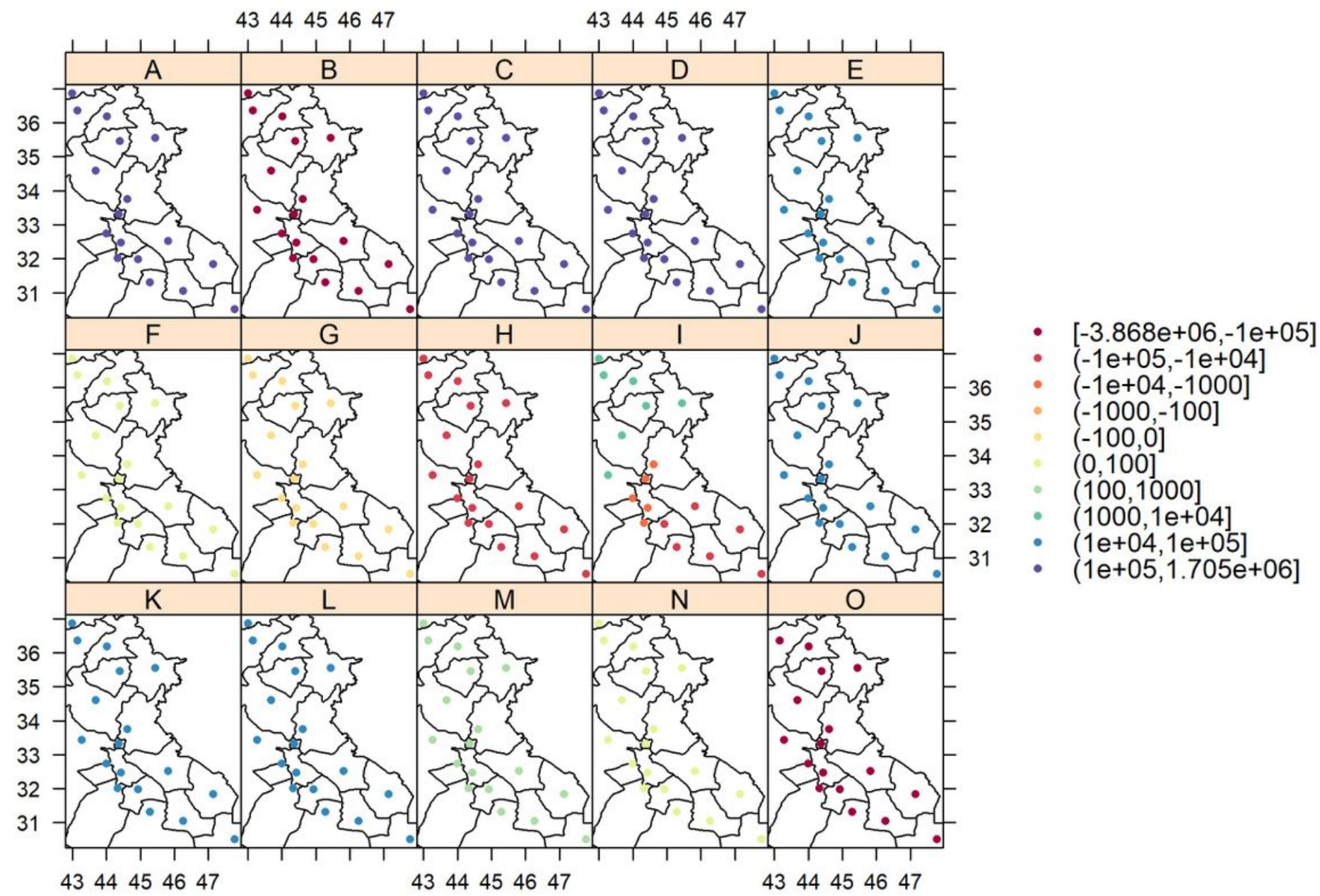

Figure 2

Relationship of total infection of COVID-19 in Iraqi Governorates and socioeconomic variables. (A) Subnational Human Development Index, (B) Health Index, (C) Standard of Living Index, (D) Education Index, (E) Life expectancy, (F) Gross National Income per Capita, (G) \% Piped water, (H) Dependency ratio, (I) \% Pop 65+, (J) Old depratio, (K) \% Pop <15, (L) Population in millions, (M) Urbanization, (N) Density, (O) Human Development Index. 